\title{
Feasibility and reliability of frailty assessment in the critically ill: a systematic review
}

Richard J. Pugh ${ }^{1 *}$ D, Amy Ellison ${ }^{1}$, Kate Pye ${ }^{2}$, Christian P. Subbe ${ }^{3}$, Chris M. Thorpe ${ }^{4}$, Nazir I. Lone ${ }^{5}$ and Andrew Clegg ${ }^{6}$

\begin{abstract}
Background: For healthcare systems, an ageing population poses challenges in the delivery of equitable and effective care. Frailty assessment has the potential to improve care in the intensive care setting, but applying assessment tools in critical illness may be problematic. The aim of this systematic review was to evaluate evidence for the feasibility and reliability of frailty assessment in critical care.

Methods: Our primary search was conducted in Medline, Medline In-process, EMBASE, CINAHL, PsycINFO, AMED, Cochrane Database of Systematic Reviews, and Web of Science (January 2001 to October 2017). We included observational studies reporting data on feasibility and reliability of frailty assessment in the critical care setting in patients 16 years and older. Feasibility was assessed in terms of timing of evaluation, the background, training and expertise required for assessors, and reliance upon proxy input. Reliability was assessed in terms of inter-rater reliability.

Results: Data from 11 study publications are included, representing 8 study cohorts and 7761 patients. Proxy involvement in frailty assessment ranged from 58 to 100\%. Feasibility data were not well-reported overall, but the exclusion rate due to lack of proxy availability ranged from 0 to $45 \%$, the highest rate observed where family involvement was mandatory and the assessment tool relatively complex (frailty index, FI). Conventional elements of frailty phenotype (FP) assessment required modification prior to use in two studies. Clinical staff tended to use a simple judgement-based tool, the clinical frailty scale (CFS). Inter-rater reliability was reported in one study using the CFS and although a good level of agreement was observed between clinician assessments, this was a small and singlecentre study.

Conclusion: Though of unproven reliability in the critically ill, CFS was the tool used most widely by critical care clinical staff. Conventional FP assessment required modification for general application in critical care, and an FIbased assessment may be difficult to deliver by the critical care team on a routine basis. There is a high reliance on proxies for frailty assessment, and the reliability of frailty assessment tools in critical care needs further evaluation.
\end{abstract}

Prospero registration number: CRD42016052073.

Keywords: Frailty, Reliability, Feasibility, Clinical frailty scale, Frailty phenotype, Frailty Index, Critical care, Intensive care, Critically ill

\footnotetext{
* Correspondence: richard.pugh@wales.nhs.uk

'Department of Anaesthetics, Glan Clwyd Hospital, Bodelwyddan,

Denbighshire, UK

Full list of author information is available at the end of the article
} 


\section{Background}

As the proportion of older patients admitted to critical care rises $[1,2]$, there is a pressing need to understand how critical care might best support a population with potentially complex medical, physical and psychosocial concerns. Only recently have studies started to explore the relevance of frailty assessment to the care of critically ill adults $[3,4]$. Related to, though distinct from, comorbidity and disability, frailty is a term used to describe "a condition characterised by loss of biological reserve and vulnerability to poor resolution of homeostasis following a stressor event" [5]. Frailty implies an impaired ability to withstand the physiological disturbance of an acute illness, and although it becomes more prevalent with age it is not exclusive to an older population.

A range of methods to evaluate frailty are described in the literature [5-8], with the utility of a particular frailty assessment tool dependent on the purpose, setting, time available, and skill of the assessor [9]. For the acutely ill, assessment tools might best be described as one of: a judgment-based measure (e.g. the clinical frailty scale (CFS) [10]); a single physical performance measure (e.g. grip strength); a frailty phenotype (depending on the presence of typically three to five criteria [11]); an extended multidimensional assessment (e.g. Tilburg Frailty Indicator $[12,13])$; and a frailty index, the number of accumulated deficits associated with adverse outcome presented as a proportion with respect to the total number (30 or more) of pre-specified possible deficits [14].

Previous systematic reviews have examined the psychometric properties of frailty assessment tools in primarily non-acute settings [6-8, 15]. However, the validity and reliability of an assessment tool is largely dependent on the setting and population in which it was developed and validated [8], and frailty assessment in the critically ill poses particular challenges. At the outset of critical illness, there is often a reliance on proxy respondents [4]. Furthermore, frailty is itself an independent risk factor for delirium, can coexist with dementia and is associated with disability [5]. Proxy ratings do not necessarily correspond with a subject's own assessment of function or quality of life during the recovery from critical illness [16-19]. Last, there is inherent risk of inadvertently ascribing features of acute illness to underlying frailty [20] and of recall bias with retrospective inquiry. Given these concerns, we aimed to systematically review the literature to establish the feasibility and reliability of frailty assessment in the critically ill.

\section{Methods}

Our review was performed according to recommendations for the systematic review of observational studies [21] and was registered prospectively via PROSPERO
(PROSPERO, https://www.crd.york.ac.uk/PROSPERO/ display_record.php?RecordID=52073) with registration number: CRD42016052073.

\section{Eligibility criteria}

The inclusion criteria were:

1. The study included adult (16 years and over) patients being managed in a critical care environment.

2. The study involved the application of a multidimensional frailty assessment tool.

3. The study presented data relating to the feasibility of frailty assessment in the critically ill (timing of evaluation, the background, training and expertise required for assessors, and reliance upon proxy input), and/or of the reliability of frailty assessment in the critically ill.

Reviews, case reports and case series were excluded; studies that collected data retrospectively were not excluded, but the potential bias associated with retrospective as opposed to prospective study was considered. Data from the control arm of randomised controlled trials (RCTs) were considered for inclusion if the trial eligibility criteria identified a study population that was representative of the general critical care population. Studies were limited to English language publications from 2001 onwards. However, there was no restriction on the basis of publication status, provided eligibility criteria were otherwise met.

\section{Information sources}

We searched the following databases from January 2001 to October 2017: Medline, Medline In-process, EMBASE, CINAHL, PsycINFO, AMED, Cochrane Database of Systematic Reviews, and Web of Science. Additional studies were sought from grey literature using the Open Grey database and by screening critical care conference abstracts, from the reference lists of papers and review articles, and through searches for full-text publication of relevant abstracts.

\section{Data management}

Two authors independently screened titles and abstracts. An additional author also contributed to hand-searching reference lists of identified papers and review articles. A spreadsheet was used to keep a log of all potentially relevant studies and reasons for inclusion or exclusion. In the event of disagreement following full-text review, consensus was achieved through discussion without recourse to a third author. Data from included studies were extracted using a standardised data collection proforma and additional information sought from trial authors where appropriate. 


\section{Data items}

Study data extraction included: author, year, publication type, country, methodology and setting. Relevant patient characteristics of studied cohorts included: demographic data (age, gender), presence of co-morbidity, evidence of baseline level of dependence, primary reason for admission, surgical status, and severity of illness (according to established illness severity scales). Timing of frailty assessment was recorded (e.g. with reference to a point in time before the acute illness, at time of referral, at time of admission to critical care, or during recovery from acute illness), and interval between assessments. Information on the participation of the patient in the frailty assessment process was collected, as was the background of the individual(s) making the assessment of frailty.

\section{Outcomes and prioritisation}

Feasibility of the frailty measurement tools in critical care was assessed on the basis of time taken to perform the assessment, training, and expertise required to implement, the proportion of potentially eligible patients excluded, and reasons for exclusion (e.g. due to lack of proxy).

Given that frailty state is not static in the context of an acute illness [4, 22], in assessing reliability our primary interest was the contemporaneous measure of inter-rater reliability. Where available, for ordinal scores we extracted the linear weighted kappa in line with consensus-based standards [23].

\section{Risk of bias for individual studies}

We did not identify any eligible RCTs, but for observational studies the risk of bias was assessed using the Newcastle-Ottawa checklist [24] according to the domains of selection, comparability, exposure, and outcome. For each domain, a judgement of low, unclear, or high risk of bias was made. Studies were considered as at overall low risk of bias if all domains were judged as low risk; studies were considered high risk if any domains were deemed high risk. Depending on number and risk of studies identified, it was intended that sensitivity analysis might be performed excluding high-risk studies.

\section{Results}

Study selection

Search results are summarised in the Preferred Reporting Items for Systematic Reviews and Meta-Analyses (PRISMA) [25] diagram (Fig. 1). There were 2180 articles identified, of which 69 were considered potentially eligible. Following full-text review, a total of 11 study publications were included [26-36], representing 8 study cohorts and a total of 7761 patients.

\section{Study characteristics}

The characteristics of included studies are summarised in Tables 1 and 2. Two research groups presented separate analyses of study cohorts in multiple publications (Bagshaw [26-28] and Heyland [33, 34]) but for the

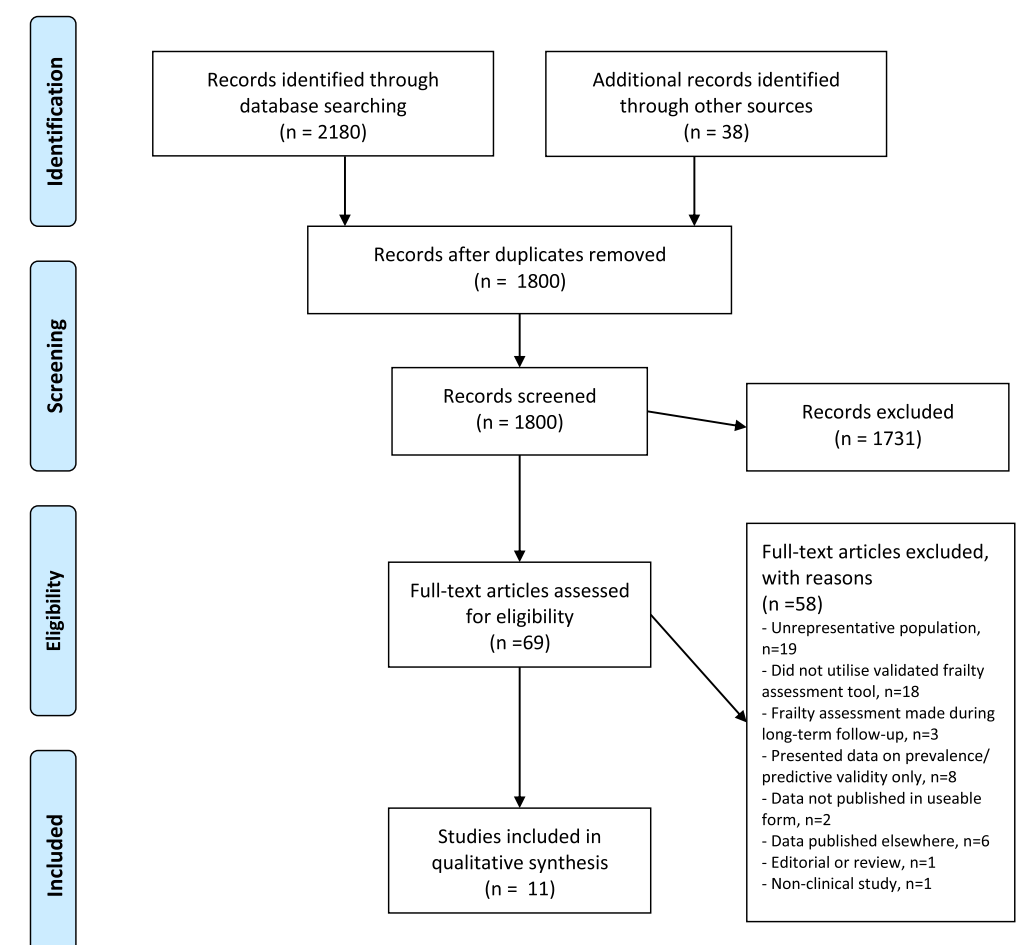

Fig. 1 Flow diagram of included studies [25] 
Table 1 Study characteristics

\begin{tabular}{|c|c|c|c|c|c|c|c|}
\hline Study & Year & Full text & $\begin{array}{l}\text { Country/ } \\
\text { countries }\end{array}$ & $\begin{array}{l}\text { Number } \\
\text { of sites }\end{array}$ & Setting & Intended study outcomes & $\begin{array}{l}\text { Additional data } \\
\text { provided by } \\
\text { study authors? }\end{array}$ \\
\hline $\begin{array}{l}\text { Bagshaw } \\
{[26-28]}\end{array}$ & $\begin{array}{l}2014,2015 \\
2016\end{array}$ & Yes & Canada & 6 & $\begin{array}{l}\text { Mixed medical- } \\
\text { surgical ICU }\end{array}$ & $\begin{array}{l}\text { Predictive validity: in-hospital } \\
\text { mortality, health-related quality } \\
\text { of life }\end{array}$ & - \\
\hline $\begin{array}{l}\text { Brummel } \\
{[29]}\end{array}$ & 2017 & Yes & USA & 5 & $\begin{array}{l}\text { Medical and } \\
\text { surgical ICU }\end{array}$ & $\begin{array}{l}\text { Predictive validity: mortality, } \\
\text { disability, cognitive impairment }\end{array}$ & Yes \\
\hline Fisher [32] & 2015 & Yes & Australia & 1 & $\begin{array}{l}\text { Mixed-medical } \\
\text { surgical ICU }\end{array}$ & $\begin{array}{l}\text { Predictive validity: mortality, length } \\
\text { of stay, discharge destination } \\
\text { Feasibility }\end{array}$ & - \\
\hline $\begin{array}{l}\text { Flaatten } \\
{[36]}\end{array}$ & 2017 & Yes & $\begin{array}{l}\text { Europe ( } 21 \\
\text { countries) }\end{array}$ & 311 & Mixed ICUs & Predictive validity: mortality & Yes \\
\hline $\begin{array}{l}\text { Heyland } \\
{[33,34]}\end{array}$ & 2015,2015 & Yes & Canada & 22 & Mixed ICUs & $\begin{array}{l}\text { Predictive validity: prolonged } \\
\text { dying experience, physical recovery } \\
\text { at } 12 \text { months }\end{array}$ & Yes \\
\hline Hope [35] & 2017 & Yes & USA & 2 & $\begin{array}{l}\text { Medical and } \\
\text { surgical ICUs }\end{array}$ & $\begin{array}{l}\text { Construct validity: frailty markers, } \\
\text { frailty assessment and demographic } \\
\text { correlates of frailty. Predictive } \\
\text { validity: new disability and death }\end{array}$ & Yes \\
\hline $\begin{array}{l}\text { Le Maguet } \\
\text { [30] }\end{array}$ & 2014 & Yes & France & 4 & $\begin{array}{l}\text { Mixed medical- } \\
\text { surgical ICU }\end{array}$ & Predictive validity: mortality & Yes \\
\hline Pugh [31] & 2017 & $\begin{array}{l}\text { No - research } \\
\text { letter only }\end{array}$ & UK & 1 & $\begin{array}{l}\text { Mixed medical- } \\
\text { surgical ICU }\end{array}$ & $\begin{array}{l}\text { Inter-rater reliability of frailty } \\
\text { assessment }\end{array}$ & Yes \\
\hline
\end{tabular}

purposes of this review each study cohort was considered as a single study. Four studies were conducted in North America [26-29, 33-35], three in Europe (including one large study involving 21 countries) [30, 31, 36] and one in Australia [32]. The majority of studies were multi-centre [26-30, 33-36] and set in mixed medicalsurgical ICUs. The median sample size was 385 patients (range 30-5021). Four of the studies adopted age restrictions: age 50 years or more [26-28], 65 years or more [30], and 80 years or more [33, 34, 36]. Only one study explicitly excluded patients with severe cognitive disease, including dementia [29]. The majority of patients were male, and $61 \%$ received invasive ventilation.

In the majority of studies, the main aim was assessment of predictive validity (e.g. in terms of mortality, length of stay, disability, and health-related quality of life). In only one study was the primary intention to evaluate reliability of frailty assessment [31], and in only one other was the feasibility of frailty assessment an explicit outcome [32]. However, each of the other six studies included presented data sufficient to enable evaluation of the feasibility of frailty assessment in critical care.

\section{Risk of bias within studies}

Six studies were considered at unclear overall risk of bias [26-31, 35, 36] and two studies were considered at low overall risk of bias [32-34] (Table 3). Regarding selection bias, the Bagshaw, Fisher, and Heyland reports were considered at low risk, since potential differences

Table 2 Patient characteristics

\begin{tabular}{|c|c|c|c|c|c|c|}
\hline Study & Number of patients & $\begin{array}{l}\text { Sex } \\
(\% \text { male) }\end{array}$ & Age restriction & $\begin{array}{l}\text { Age in years, mean } \\
(+/-\mathrm{SD}) \text { or median (IQR) }\end{array}$ & Operative status & $\begin{array}{l}\text { Proportion receiving } \\
\text { invasive ventilation }\end{array}$ \\
\hline Bagshaw [26-28] & 421 & $61 \%$ & 50 Years and older ${ }^{a}$ & $67+/-10$ & Post-operative: 34\% & $86 \%$ \\
\hline Brummel [29] & 1040 & $60 \%$ & 18 Years and older & $62(53-72)$ & Post-operative: $16 \%$ & $88 \%$ \\
\hline Fisher [32] & 348 & $59 \%{ }^{b}$ & 18 Years and older & $60(+/-17)$ & Post-operative: 53\% & Not reported \\
\hline Flaatten [36] & 5021 & $52 \%$ & 80 Years and older & $84(81-86)$ & Post-operative: $27 \%$ & $51 \%$ \\
\hline Heyland $[33,34]$ & 610 & $55 \%$ & 80 Years and older & $84(+/-3)$ & Post-operative: $39 \%$ & $72 \%$ \\
\hline Hope [35] & 95 & $56 \%$ & None & $57(+/-18)$ & Post-operative: $6 \%$ & $56 \%$ \\
\hline Le Maguet [30] & 196 & $65 \%$ & 65 Years and older & $75(+/-6)$ & Post-operative: $65 \%$ & $88 \%$ \\
\hline Pugh [31] & 30 & $60 \%$ & 16 Years and older & $67(+/-14)$ & Not collected & Not collected \\
\hline
\end{tabular}

abaghaw (2016) focused on patients aged 50-64.9 years of age [28]

${ }^{\mathrm{b}}$ Among patients undergoing clinical frailty scale assessment 
Table 3 Risk of bias in included studies, with regards to feasibility and reliability

\begin{tabular}{|c|c|c|c|c|c|}
\hline \multirow[t]{2}{*}{ Study } & \multicolumn{4}{|l|}{ Risk of bias } & \multirow[t]{2}{*}{ Notes } \\
\hline & Selection bias $^{a}$ & Comparability $^{b}$ & Outcome $^{c}$ & Overall risk & \\
\hline Bagshaw [26-28] & Low & Unclear & $\mathrm{n} / \mathrm{a}$ & Unclear & $\begin{array}{l}\text { No statistically significant differences between study participants } \\
\text { and non-enrolled. Involvement of proxy vs. patient not specified. }\end{array}$ \\
\hline Brummel [29] & Unclear & Unclear & $\mathrm{n} / \mathrm{a}$ & Unclear & $\begin{array}{l}\text { Reasons for non-enrolment described, but potential differences } \\
\text { between such patients not explored. Timing of frailty assessment } \\
\text { described, but data regarding proxy involvement not collected. }\end{array}$ \\
\hline Fisher [32] & Low & Low & $\mathrm{n} / \mathrm{a}$ & Low & $\begin{array}{l}\text { Reasons for not evaluating frailty not recorded, though there is } \\
\text { comparison of evaluated vs. non-evaluated patients. }\end{array}$ \\
\hline Flaatten [36] & Unclear & Unclear & $\mathrm{n} / \mathrm{a}$ & Unclear & $\begin{array}{l}\text { Numbers of potentially eligible patients not enrolled and reasons } \\
\text { for non-enrolment not collated. Proxy data not collected. }\end{array}$ \\
\hline Heyland [33, 34] & Low & Low & n/a & Low & $\begin{array}{l}\text { Characteristics of study cohort were similar to unselected hospital } \\
\text { cohort. }\end{array}$ \\
\hline Hope [35] & Unclear & Low & $\mathrm{n} / \mathrm{a}$ & Unclear & $\begin{array}{l}\text { Reasons for non-enrolment described, but potential differences } \\
\text { between such patients and those enrolled not studied. Proxy } \\
\text { involvement described. }\end{array}$ \\
\hline Le Maguet [30] & Unclear & Unclear & $\mathrm{n} / \mathrm{a}$ & Unclear & $\begin{array}{l}\text { Reasons for non-inclusion partially described. Potential differences } \\
\text { between included and excluded patients not investigated. }\end{array}$ \\
\hline Pugh [31] & Unclear & Unclear & Low & Unclear & $\begin{array}{l}\text { Reasons for non-enrolment not recorded nor details regarding } \\
\text { proxy involvement. Interval between assessments not recorded. } \\
\text { Assessors were blinded to other assessments. }\end{array}$ \\
\hline
\end{tabular}

$n / a$ not analysed

${ }^{a}$ Study group truly representative of critically ill population, reasons for non-inclusion are described, differences between included and excluded eligible patients analysed

${ }^{b}$ Description of proxy involvement, timing of assessments, interval between assessments, staff involved in assessments

${ }^{c}$ Investigating reliability of assessment, assessments performed independently and blindly analysed

between patients recruited and not recruited had been explored [26-28, 32-34]. In terms of comparability, the Fisher, Heyland, and Hope reports were considered at low risk of bias, since in these studies the proxy contribution to assessment of frailty was quantified [32-35]. Only one study explored the reliability of frailty assessment, for which outcome bias was considered low risk due to the adoption of blinded assessment [31]. No studies were considered high risk and sensitivity analysis was therefore not performed.

\section{Assessment of frailty}

All studies evaluated frailty using a clinical frailty scale (CFS) [10]; six studies used a 9-point scale [26-28, 30, 31, 35, 36] (see Fig. 2) and two a 7-point scale $[29,33,34]$. Additional scoring systems were used in three studies [30, 33-35]. Two studies utilised a frailty phenotype (FP) assessment, identifying frailty on the basis of the following domains: shrinking, weakness, slowness, low-level physical activity, and self-reported exhaustion [11], but modified for use in the critically ill (see Table 4) [30, 35]. Furthermore, Hope and colleagues supplemented these FP domains with questions relating to cognitive and to sensory impairment [35]. One study utilised a frailty index based on a 43-item comprehensive geriatric assessment (CGA) [33, 34].
Timing of frailty assessment was available in seven studies. Frailty was assessed at critical care admission [30], within the first 24 hours $[32,36]$ or first 72 hours of critical care admission [29, 33-35] (Table 5). A variety of reference points for assessment were adopted: the subject's condition before ICU admission [32], before hospital admission [26-28], before onset of critical illness [29], before acute illness and hospital admission [36], 2 weeks before hospital admission [31, 33, 34] or one month before hospital admission [30].

\section{Feasibility of frailty assessment}

A member of the research team assessed frailty in five studies [26-29, 31, 33-35]; in three studies critical care doctors with clinical rather than research responsibilities assessed frailty using a CFS $[31,35]$ or a CFS and FP [30]; in one study critical care nurses and doctors assessed frailty using a CFS [36], and in one study it was the nurse-in-charge or next-of-kin (with nurse guidance) who assigned a CFS score [32] (Table 6). Researchers received specific training to familiarise themselves with the study and assessment tool(s) in four studies [29, 31, 33-35]; critical care nurses received CFS training in the form of a series of lectures in one study [32]. In the remaining three studies, training clinical staff to use CFS took place in a staff meeting [30], at the bedside [31, 35] or was 


\section{Clinical Frailty Scale*}

I Very Fit - People who are robust, active, energeti and motivated. These people commonly exercise regularly. They are among the fittest for their age.

2 Well-People who have no active disease symptoms but are less fit than category I. Often, they exercise or are very active occasionally, e.g. seasonally

3 Managing Well - People whose medical problems are well controlled, but are not regularly active beyond routine walking.

4 Vulnerable - While not dependent on others for daily help, often symptoms limit activities. A common complaint is being "slowed up", and/or being tired during the day.

5 Mildly Frail - These people often have more evident slowing, and need help in high order IADL (finances, transportation, heavy housework, medications). Typically, mild frailty progressively impairs shopping and walking outside alone, meal preparation and housework

A 6 Moderately Frail - People need help with all outside activities and with keeping house. Inside, they

11. often have problems with stairs and need help with bathing and might need minimal assistance (cuing, standby) with dressing.
我

7 Severely Frail - Completely dependent for personal care from whatever cause (physical or cognitive). Even so, they seem stable and not at high risk of dying (within $\sim 6$ months).

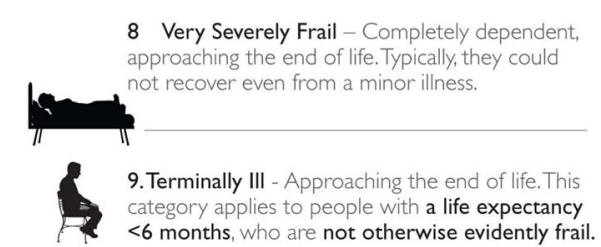

Scoring frailty in people with dementia

The degree of frailty corresponds to the degree of dementia. Common symptoms in mild dementia include forgetting the details of a recent event, though still remembering the event itself repeating the same question/story and social withdrawal.

In moderate dementia, recent memory is very impaired, even though they seemingly can remember their past life events well. They can do personal care with prompting.

In severe dementia, they cannot do personal care without help.

* 1. Canadian Study on Health \& Aging, Revised 2008. $2 \mathrm{~K}$. Rockwood et al. A global clinical measure of fitness and frailty in elderly people. CMA) 2005; 733:489-495. Q 2007-2009. Version 1.2.All rights reserved Geratric Medicine

Fig. 2 Clinical frailty scale [10]

Table 4 Assessment of frailty according to frailty phenotype

\begin{tabular}{|c|c|c|c|}
\hline Frailty domain & Fried [11] & Le Maguet [30] & Hope [35] \\
\hline Shrinking & $\begin{array}{l}\text { Unintentional (not due to dieting or } \\
\text { exercise) weight loss } 10 \mathrm{lbs}(4.5 \mathrm{~kg} \text { ) } \\
\text { or more than } 5 \% \text { of body weight in } \\
\text { the prior year }\end{array}$ & $\begin{array}{l}\text { Unintentional (not due to dieting or } \\
\text { exercise) weight loss } \geq 4.5 \mathrm{~kg} \text { or more } \\
\text { than } 5 \% \text { of body weight in the prior } \\
\text { year }\end{array}$ & $\begin{array}{l}\text { Reported weight loss and } \mathrm{BMI}<24 \text { or } \geq 5 \% \\
\text { weight loss }\end{array}$ \\
\hline Weakness & $\begin{array}{l}\text { Hand-grip strength measured by } \\
\text { dynamometer (stratified by gender } \\
\text { and body mass index) }\end{array}$ & Difficulty rising from a chair & $\begin{array}{l}\text { Unable to rise from a chair without using } \\
\text { arms }\end{array}$ \\
\hline
\end{tabular}

Slowness Time to walk 15 feet (stratified by gender and height)

Low physical activity

Use of Minnesota Leisure Time Activity Questionnaire to calculate kilocalories expended per week

Exhaustion

Feeling that everything the patient does is an effort and/or the feeling that he/she could not get going, and how often in the last 3 months he/she felt this way
Slowed walking speed (during the last 6 months, with difficulties walking and with aid) and/or the occurrence of fall(s)

Discontinued daily leisure activities such as walking or gardening and/or discontinued some sport activity per week

Feeling that everything the patient does is an effort and/or the feeling that he/she could not get going, and how often in the last 3 months he/she felt this way
Falls or need for assistance with mobility inside or outside the home in the past year

Unable to climb flight of stairs or undertake moderate activity, e.g. pushing a vacuum cleaner or bowling

Feeling that everything the patient does is an effort and/or the feeling that he could not get going, in past 4 weeks; number of times he/she had a lot of energy in past 4 weeks

Memory Impairment Screen, or modified version of the Short-Form Informant Questionnaire on Cognitive Decline in the Elderly

Problems in daily life because of poor vision or impaired hearing in last year 
Table $\mathbf{5}$ Issues relating to frailty assessment

\begin{tabular}{|c|c|c|c|c|}
\hline Study & Frailty assessment tool & Timing of frailty assessment & Reference point for frailty assessment & $\begin{array}{l}\text { Interval between } \\
\text { assessments }\end{array}$ \\
\hline Bagshaw [26-28] & CFS & Not recorded & Immediately before hospitalisation & Not applicable \\
\hline Brummel [29] & CFS & Within 72 hours of ICU admission & Prior to critical illness & Not applicable \\
\hline Fisher [32] & CFS & $\begin{array}{l}\text { Within first } 24 \text { hours of ICU admission } \\
\text { (for next-of-kin) }\end{array}$ & Pre-ICU admission & Not applicable \\
\hline Flaatten [36] & CFS & Within first 24 hours of ICU admission & Before acute illness and hospital admission & Not applicable \\
\hline Heyland [33, 34] & $\begin{array}{l}\text { CFS, } \\
\mathrm{FI}\end{array}$ & At $48-72$ hours after ICU admission & At 2 weeks pre-hospital admission & Not recorded \\
\hline Hope [35] & $\begin{array}{l}\text { CFS, } \\
\text { FP }\end{array}$ & Within 72 hours of ICU admission & $\begin{array}{l}\text { CFS: not specified FP: variable, depending } \\
\text { on element }\end{array}$ & Within 24 hours \\
\hline Le Maguet [30] & $\begin{array}{l}\text { CFS, } \\
\text { FP }\end{array}$ & At ICU admission & At 1 month pre-hospital admission & Not recorded \\
\hline Pugh [31] & CFS & Not recorded & At 2 weeks pre- hospital admission & Not recorded \\
\hline
\end{tabular}

FP frailty phenotype, CFS clinical frailty score, $n / a$ not analysed

deemed not to need particular training "since the description combined with illustration is intuitive" [36]. The times required for training and to perform assessments were for the most part not captured during the course of included studies (Table 6).

Two studies excluded patient involvement in frailty assessment in their methodology [32-34]. Of these, availability of a family member was a requirement for study enrolment in Heyland's study [33, 34]. In Fisher's study, the CFS assessment was expected to be made by the next-of-kin under the guidance of the bedside nurse, using a standardised introduction; however, CFS assessment was made by the nurse-in-charge if the next-of-kin was unavailable in the first 24 hours of critical care admission [32]. The researchers reported that when no assessment had been made, patients were more likely to have been post-operative or to have had a shorter critical care stay. In Le Maguet [30], 31\% of patients were able to interact with an interviewer to enable assessment, and in Hope [35], 42\% patients contributed to frailty assessment. In the other three studies, patient participation was not recorded.

Where recorded, a proxy was involved in 58\% [35], 69\% [30], 73\% [32] and 100\% [33, 34] of frailty assessments (Table 6). Fisher found that it was not possible to approach the next of kin for involvement in assessment in $27 \%$ cases within the first 24 hours of critical care admission; however, since the nurse in charge could make a CFS assessment on the basis of medical records, this did not prohibit frailty assessment [32]. Flaatten did not specify the contribution of patient or proxy to assessment, but noted that CFS assessment was achieved in $99.8 \%$ of cases included [36]. Hope noted that in some instances surrogates were unable to answer questions relating to an assessment of frailty according to FP assessment, for example, according to domains of weight loss (5\% of cases) or loss of energy (3\% of cases) [35]. Le Maguet also found that "several components of the FP score, notably those that evaluate performance, were difficult to explore in ICU patients" [30]. Overall, screened patients excluded from enrolment due to lack of proxy availability ranged from 0 to $45 \%$ in five studies [29, 30, 32-35]: the highest exclusion rate was in Heyland's study, in which frailty was assessed according to a 43-item CGA and a CFS, and in which family involvement was an absolute requirement for enrolment [33, 34].

\section{Reliability of frailty assessment}

Reliability of frailty assessment was assessed in only one study, which evaluated the inter-rater reliability of frailty assessment using a CFS as a comparison between two groups, a group of medical students and a group of critical care doctors. Linear weighted kappa was 0.64 (95\% confidence intervals 0.40 to $0.87, p<0.0001$ ), suggesting good agreement. However, this was a small $(n=30)$, single-centre study comparing only two groups of assessors (medical students and critical care doctors, excluding other members of the clinical team), and which did not make reference to the relative contributions of the critical care patient or a proxy.

\section{Discussion}

In assessing the feasibility of frailty assessment, we have made a distinction between those primarily involved in clinical and in research roles in view of anticipated differences in training and time available to apply assessment tools. Though not well-described, clinical staff for the most part appear to have received relatively little training with regards the application of frailty assessment tools compared with those described as "research coordinator" or "study personnel." Despite this, the high proportion of patients among included studies undergoing frailty assessment using the judgement-based CFS by clinical staff is likely to reflect its simplicity and ease of 


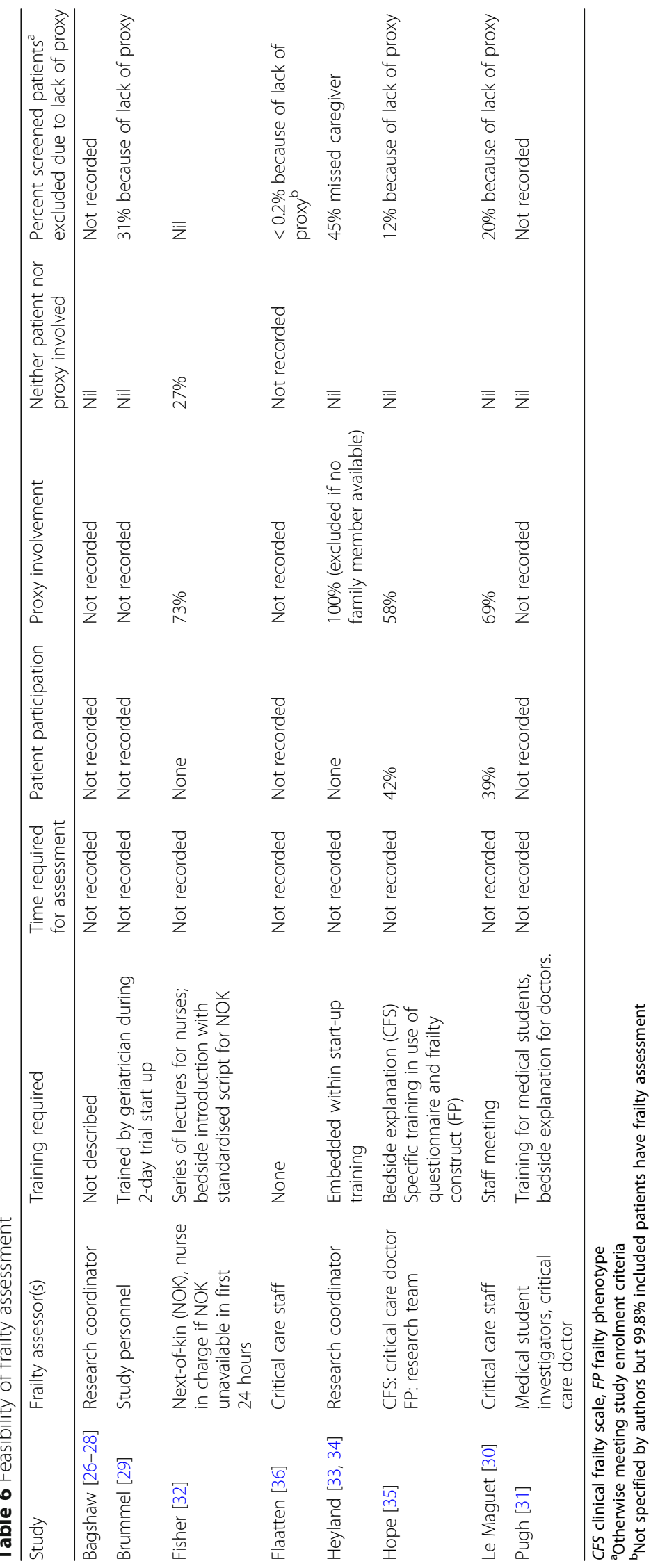


application [36]. Indeed CFS assessment seemed achievable even in the absence of family contact [32].

With regard to other assessment methods, the two studies utilising FP assessment reported difficulties with some components of FP assessment, despite making adaptations for a critically ill population. However, FP assessment was used by both clinical [30] and research staff [35]. The early phase of critical illness typically precludes elements of frailty assessment, which require demonstration rather than description (e.g. grip strength and gait speed), though such assessment appears feasible for ICU survivors much nearer to hospital discharge [37]. The consequences of such modifications for frailty classification and predictive validity in this population are uncertain [38]. FI-CGA was used to assess frailty in only one study, and although the time required to administer the 43-item questionnaire to a family member by the research coordinator was not recorded, it is unclear whether this would be too time-consuming to be feasibly delivered by a critical care team on a routine basis. Recent research has reported the development and validation of a 36-item electronic frailty index (eFI) using routinely available electronic medical record (EMR) data [39], which may be an attractive approach for critical care but requires further validation in this context.

A high proportion of enrolled patients were invasively ventilated and only a minority able to participate directly in frailty assessment. There is clearly a heavy reliance on proxy input for frailty assessment in this population, particularly when detailed information is required [32-34], and Heyland's study illustrates the difficulty of coordinating the availability of assessor and an appropriate family member when FI-CGA assessment is made by a limited number of trained individuals.

A dependence on proxy input is also highly relevant when considering the reliability of frailty assessment in the critically ill. We identified only one small clinical study that investigated the inter-rater reliability of CFS assessment between a group of critical care doctors and a group of medical students [31]. Although there was a good level of agreement, the study did not capture the relative contributions of the patient or their proxies to frailty assessment. Furthermore, we found no study that had attempted to compare assessment of frailty between clinical staff and critically ill patients or their relatives, or to evaluate the influence of clinical background, seniority, and training on frailty assessment. When carefully selected, other investigators have identified a high level of agreement between subject and proxy in terms of functional status after critical illness [40]. However, the retrospective nature of frailty assessment (in the manner identified in included studies) makes it prone to recall bias, particularly in the context of acute and sub-acute chronic illness [14, 41]. Furthermore, subjective elements (e.g. "exhaustion" [30, 35]) rather than observable criteria may be especially susceptible to differences between proxy and subject ratings $[42,43]$. The reliability of frailty assessment by clinicians is an important issue; in other settings, escalation decision-making following emergency admission may be made on the basis of a perception of baseline cognitive and functional status, which at best only modestly correlates with that of patient or relative [44].

There are several strengths to this review. We prospectively registered our review protocol and have followed rigorous methodology to identify, evaluate, and summarise the current evidence on feasibility and reliability of frailty assessments in the critically ill. However, we recognise some limitations. Assessment of the feasibility and reliability of frailty assessment was the intended outcome of only two of the eight studies included, and this is reflected in absent or incomplete data on factors that may have contributed to inclusion or exclusion of patients (e.g. to "missed caregiver"), the background of assessor, the training and time taken to perform assessment, background of any proxies, and the relative involvement of patient and proxy in the assessments. As a consequence, for the purposes of evaluating feasibility and/or reliability of frailty assessment in the critically ill, only two studies were considered at low overall risk of bias.

However, our review has a number of implications for clinical practice. We found evidence that frailty assessment can feasibly be performed by different clinical members of the critical care team (whether physician, nurse or medical student), that patient participation in such assessment will be achieved in a minority of cases, and that a qualifying proxy is usually required. We found limited data indicating that frailty can be reliably assessed by clinicians in the critical care setting. Given the challenges inherent in frailty assessment in critical illness, more research is needed regarding the reliability of frailty assessment tools in critical care before frailty assessment can be used to aid clinical decision-making and/or trigger interventions.

This review highlights areas for future research. Frailty is a dynamic state, and frailty assessment in the context of variations in health trajectories prior to critical illness needs exploration. Further study is required to compare the relative performance of frailty assessment tools in critical care, taking into account the reference point for assessment, the background and training of the assessor(s), the capacity of the patient, and the relationship between patient and proxy. In particular, the relative performance of frailty assessment using routinely captured data versus bedside frailty assessment should be evaluated in this population. Last, a clearer understanding of the training required and the time taken to make an assessment of frailty needs to be 
considered in the context of the potential benefits of making that assessment.

\section{Conclusions}

This review has found little evidence of reliability and only limited evidence on the feasibility of frailty assessment in the critically ill. CFS was the most widely applied assessment tool by clinical staff, conventional FP assessment required modification for general application in critical care, and FI-based assessment may be difficult to deliver by the critical care team on a routine basis. Additional research is required to investigate the resource implications of routine use of frailty tools, to evaluate reliability when used by a range of clinical personnel, to investigate the use of routinely available EMR data for identifying frailty, and to study reliability in the presence or absence of clinical proxies before recommending widespread application in routine critical care practice.

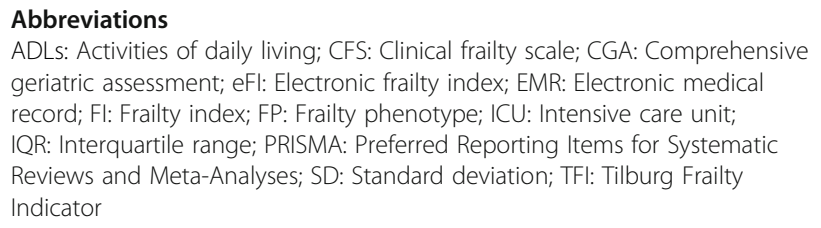
geriatric assessment; eFl: Electronic frailty index; EMR: Electronic medical record; FI: Frailty index; FP: Frailty phenotype; ICU: Intensive care unit; IQR: Interquartile range; PRISMA: Preferred Reporting Items for Systematic Reviews and Meta-Analyses; SD: Standard deviation; TFI: Tilburg Frailty Indicator

\section{Acknowledgements}

The authors are very grateful for the assistance of Deidre Andre, Research Librarian at the University of Leeds, with the design and conduct of the search strategies, and to Nia Morris, Clinical Librarian at Betsi Cadwaldr University Health Board, for her help re-running the search strategies. We are also extremely grateful for the additional information provided by the following study authors: Nathan Brummel, Hans Flaatten, Daren Heyland, Aluko Hope and Philippe Seguin.

\section{Funding}

This study was unfunded.

\section{Availability of data and material}

The datasets used and/or analysed during the current study are available from the corresponding author on reasonable request.

\section{Authors' contributions}

$R P, C T, C S, N L$, and $A C$ conceived the idea for this systematic review. RP and AC contributed to design of the review. All authors read and approved the final manuscript.

\section{Ethics approval and consent to participate}

Not applicable.

\section{Consent for publication}

Not applicable.

\section{Competing interests}

The authors declare that they have no competing interests.

\section{Publisher's Note}

Springer Nature remains neutral with regard to jurisdictional claims in published maps and institutional affiliations.

\section{Author details}

'Department of Anaesthetics, Glan Clwyd Hospital, Bodelwyddan, Denbighshire, UK. ${ }^{2}$ Bradford Teaching Hospitals NHS Foundation Trust,
Bradford, UK. ${ }^{3}$ School of Medical Sciences, Bangor University, Bangor, UK. ${ }^{4}$ Department of Anaesthetics, Ysbyty Gwynedd, Bangor, UK. ${ }^{5}$ Department of Anaesthesia, Critical Care and Pain Medicine, University of Edinburgh, Edinburgh, UK. ${ }^{6}$ Academic Unit of Elderly Care and Rehabilitation, University of Leeds, Leeds, UK.

Received: 6 October 2017 Accepted: 12 January 2018

Published online: 26 February 2018

\section{References}

1. Bagshaw SM, Webb SA, Delaney A, George C, Pilcher D, Hart GK, Bellomo R. Very old patients admitted to intensive care in Australia and New Zealand: a multi-centre cohort analysis. Crit Care. 2009;13(2):R45.

2. Ihra GC, Lehberger J, Hochrieser H, Bauer P, Schmutz R, Metnitz B, Metnitz PG. Development of demographics and outcome of very old critically ill patients admitted to intensive care units. Intensive Care Med. 2012;38(4):620-6.

3 Muscedere J, Waters B, Varambally A, Bagshaw SM, Boyd JG, Maslove D, Sibley S, Rockwood K. The impact of frailty on intensive care unit outcomes: a systematic review and meta-analysis. Intensive Care Med. 2017; 43(8):1105-22.

4 McDermid RC, Stelfox HT, Bagshaw SM. Frailty in the critically ill: a novel concept. Crit Care. 2011;15(1):301.

5 Clegg A, Young J, lliffe S, Rikkert MO, Rockwood K. Frailty in elderly people. Lancet. 2013;381(9868):752-62.

6 de Vries NM, Staal JB, van Ravensberg CD, Hobbelen JS, Olde Rikkert MG. Nijhuis-van der Sanden MW. Outcome instruments to measure frailty: a systematic review. Ageing Res Rev. 2011;10(1):104-14.

7 Dent E, Kowal P, Hoogendijk EO. Frailty measurement in research and clinical practice: a review. Eur J Intern Med. 2016;31:3-10.

8 Sutton JL, Gould RL, Daley S, Coulson MC, Ward EV, Butler AM, Nunn SP, Howard RJ. Psychometric properties of multicomponent tools designed to assess frailty in older adults: a systematic review. BMC Geriatr. 2016;16:55.

9 Buta BJ, Walston JD, Godino JG, Park M, Kalyani RR, Xue QL, Bandeen-Roche K, Varadhan R. Frailty assessment instruments: systematic characterization of the uses and contexts of highly-cited instruments. Ageing Res Rev. 2016;26:53-61.

10 Rockwood K, Song X, MacKnight C, Bergman H, Hogan DB, McDowell I, Mitnitski A. A global clinical measure of fitness and frailty in elderly people. CMAJ. 2005;173(5):489-95.

11 Fried LP, Tangen CM, Walston J, Newman AB, Hirsch C, Gottdiener J, Seeman T, Tracy R, Kop WJ, Burke G, et al. Frailty in older adults: evidence for a phenotype. J Gerontol A Biol Sci Med Sci. 2001;56(3):M146-56.

12 Gobbens RJ, van Assen MA, Luijkx KG, Wijnen-Sponselee MT, Schols JM. The Tilburg Frailty Indicator: psychometric properties. J Am Med Dir Assoc. 2010;11(5):344-55

13 Jones DM, Song X, Rockwood K. Operationalizing a frailty index from a standardized comprehensive geriatric assessment. J Am Geriatr Soc. 2004:52(11):1929-33.

14 Hogan DB, Maxwell CJ, Afilalo J, Arora RC, Bagshaw SM, Basran J, Bergman $H$, Bronskill SE, Carter CA, Dixon E, et al. A scoping review of frailty and acute care in middle-aged and older individuals with recommendations for future research. Can Geriatr J. 2017;20(1):22-37.

15 Apostolo J, Cooke R, Bobrowicz-Campos E, Santana S, Marcucci M, Cano A, Vollenbroek-Hutten M, Germini F, Holland C. Predicting risk and outcomes for frail older adults: an umbrella review of frailty screening tools. JBI Database System Rev Implement Rep. 2017;15(4):1154-208.

16 Neumann PJ, Araki SS, Gutterman EM. The use of proxy respondents in studies of older adults: lessons, challenges, and opportunities. J Am Geriatr Soc. 2000;48(12):1646-54.

17 Li M, Harris I, Lu ZK. Differences in proxy-reported and patient-reported outcomes: assessing health and functional status among medicare beneficiaries. BMC Med Res Methodol. 2015;15:62.

18 Scales DC, Tansey CM, Matte A, Herridge MS. Difference in reported pre-morbid health-related quality of life between ARDS survivors and their substitute decision makers. Intensive Care Med. 2006;32(11):1826-31.

19 Dinglas VD, Gifford JM, Husain N, Colantuoni E, Needham DM. Quality of life before intensive care using EQ-5D: patient versus proxy responses. Crit Care Med. 2013;41(1):9-14. 
20 Hilmer SN, Perera V, Mitchell S, Murnion BP, Dent J, Bajorek B, Matthews S, Rolfson DB. The assessment of frailty in older people in acute care. Australas J Ageing. 2009;28(4):182-8.

21 Stroup DF, Berlin JA, Morton SC, Olkin I, Williamson GD, Rennie D, Moher D, Becker BJ, Sipe TA, Thacker SB. Meta-analysis of observational studies in epidemiology: a proposal for reporting. Meta-analysis Of Observational Studies in Epidemiology (MOOSE) group. JAMA. 2000;283(15):2008-12.

22 Turner G, Clegg A: Best practice guidelines for the management of frailty: a British Geriatrics Society, Age UK and Royal College of General Practitioners report; 2014

23 Mokkink LB, Terwee CB, Patrick DL, Alonso J, Stratford PW, Knol DL, Bouter LM, de Vet HC. The COSMIN checklist for assessing the methodological quality of studies on measurement properties of health status measurement instruments: an international Delphi study. Qual Life Res. 2010;19(4):539-49.

24 The Newcastle-Ottawa Scale (NOS) for assessing the quality of nonrandomised studies in meta-analyses [http://www.ohri.ca/programs/clinical_epidemiology/ oxford.asp]. Accessed 10 Apr 2017.

25 Moher D, Liberati A, Tetzlaff J, Altman DG, Group P. Preferred reporting items for systematic reviews and meta-analyses: the PRISMA statement. PLoS Med. 2009;6(7):e1000097.

26 Bagshaw SM, Stelfox HT, McDermid RC, Rolfson DB, Tsuyuki RT, Baig N, Artiuch B, Ibrahim Q, Stollery DE, Rokosh E, et al. Association between frailty and short- and long-term outcomes among critically ill patients: a multicentre prospective cohort study. Can Med Assoc J. 2014;186(2):E95-E102.

27 Bagshaw SM, Stelfox HT, Johnson JA, McDermid RC, Rolfson DB, Tsuyuki RT, Ibrahim Q, Majumdar SR. Long-Term Association Between Frailty and Health-Related Quality of Life Among Survivors of Critical IIIness: a prospective multicenter cohort study. Crit Care Med. 2015;43(5):973-82.

28 Bagshaw M, Majumdar SR, Rolfson DB, Ibrahim Q, McDermid RC, Stelfox HT. A prospective multicenter cohort study of frailty in younger critically ill patients. Crit Care. 2016;20(1):175. Erratum in: Crit Care. 2016;20(1):223.

29 Brummel NE, Bell SP, Girard TD, Pandharipande PP, Jackson JC, Morandi A, Thompson JL, Chandrasekhar R, Bernard GR, Dittus RS, et al. Frailty and subsequent disability and mortality among patients with critical illness. Am J Respir Crit Care Med. 2017;196(1):64-72.

30 Le Maquet P, Roquilly A, Lasocki S, Asehnoune K, Carise E, Saint Martin M, Mimoz O, Le Gac G, Somme D, Cattenoz C, et al. Prevalence and impact of frailty on mortality in elderly ICU patients: a prospective, multicenter, observational study. Intensive Care Med. 2014;40(5):674-82.

31 Pugh RJ, Thorpe CM, Subbe CP. A critical age: can we reliably measure frailty in critical care? Crit Care. 2017;21(1):121.

32 Fisher C, Karalapillai DK, Bailey M, Glassford NG, Bellomo R, Jones D. Predicting intensive care and hospital outcome with the Dalhousie Clinical Frailty Scale: a pilot assessment. Anaesth Intensive Care. 2015;43(3):361-8

33 Heyland DK, Garland A, Bagshaw SM, Cook D, Rockwood K, Stelfox HT, Dodek P, Fowler RA, Turgeon AF, Burns K, et al. Recovery after critical illness in patients aged 80 years or older: a multi-center prospective observational cohort study. Intensive Care Med. 2015;41(11):1911-20.

34 Heyland D, Cook D, Bagshaw SM, Garland A, Stelfox HT, Mehta S, Dodek P, Kutsogiannis J, Burns K, Muscedere J, et al. The very elderly admitted to ICU: a quality finish? Crit Care Med. 2015;43(7):1352-60.

35 Hope AA, Hsieh SJ, Petti A, Hurtado-Sbordoni M, Verghese J, Gong MN. Assessing the usefulness and validity of frailty markers in critically ill adults. Ann Am Thorac Soc. 2017;14(6):952-9.

36 Flaatten H, De Lange DW, Morandi A, Andersen FH, Artigas A, Bertolini G, Boumendil A, Cecconi M, Christensen S, Faraldi L, et al. The impact of frailty on ICU and 30-day mortality and the level of care in very elderly patients (>/= 80 years). Intensive Care Med. 2017;43(12):1820-1828.

37 Baldwin MR, Reid MC, Westlake AA, Rowe JW, Granieri EC, Wunsch H, Dam $T$, Rabinowitz D, Goldstein NE, Maurer MS, et al. The feasibility of measuring frailty to predict disability and mortality in older medical intensive care unit survivors. J Crit Care. 2014;29(3):401-8.

38 Theou O, Cann L, Blodgett J, Wallace LM, Brothers TD, Rockwood K. Modifications to the frailty phenotype criteria: Systematic review of the current literature and investigation of 262 frailty phenotypes in the Survey of Health, Ageing, and Retirement in Europe. Ageing Res Rev. 2015;21:78-94

39 Clegg A, Bates C, Young J, Ryan R, Nichols L, Ann Teale E, Mohammed MA, Parry J, Marshall T. Development and validation of an electronic frailty index using routine primary care electronic health record data. Age Ageing. 2016; 45(3):353-60.
40 Ahasic AM, Van Ness PH, Murphy TE, Araujo KL, Pisani MA. Functional status after critical illness: agreement between patient and proxy assessments. Age Ageing. 2015;44(3):506-10.

41 Iwashyna TJ. Trajectories of recovery and dysfunction after acute illness, with implications for clinical trial design. Am J Respir Crit Care Med. 2012;186(4):302-4.

42 Carod-Artal FJ, Ferreira Coral L, Stieven Trizotto D, Menezes MC. Self- and proxy-report agreement on the Stroke Impact Scale. Stroke. 2009:40(10):3308-14.

43 Oczkowski C, O'Donnell M. Reliability of proxy respondents for patients with stroke: a systematic review. J Stroke Cerebrovasc Dis. 2010;19(5):410-6.

44 Rodriguez-Molinero A, Lopez-Diequez M, Tabuenca Al, de la Cruz Jل رل Banegas JR. Physicians' impression on the elders' functionality influences decision making for emergency care. Am J Emerg Med. 2010;28(7):757-65.

\section{Submit your next manuscript to BioMed Central and we will help you at every step:}

- We accept pre-submission inquiries

- Our selector tool helps you to find the most relevant journal

- We provide round the clock customer support

- Convenient online submission

- Thorough peer review

- Inclusion in PubMed and all major indexing services

- Maximum visibility for your research

Submit your manuscript at www.biomedcentral.com/submit
) Biomed Central 